\title{
Performance of Mechanical Filters and Respirators for Capturing Nanoparticles —Limitations and Future Direction
}

\author{
Reza MOSTOFI' ${ }^{1}$, Bei WANG ${ }^{1}$, Fariborz HAGHIGHAT ${ }^{*}$, Ali BAHLOUL ${ }^{2}$ and Lara JAIME$^{2}$ \\ ${ }^{1}$ Department of Building, Civil and Environmental Engineering, Concordia University, 1455 de Maisonneuve \\ Blvd. W., Montreal, Quebec H3G 1M8, Canada \\ ${ }^{2}$ Institut de recherche Robert-Sauvé en santé et en sécurité du travail (IRSST), 505, Blvd. de Maisonneuve \\ Ouest, Montreal, Quebec H3A 3C2, Canada
}

Received July 27, 2009 and accepted October 20, 2009

\begin{abstract}
There is an increasing concern about the health hazard posed to workers exposed to inhalation of nanoparticles. Inhaling nanoparticles posses an occupational hazard due to elevated amount emitted to the atmosphere and working environment. Nanoparticles have potential toxic properties: the high particle surface area, number concentration, and surface reactivity. Inhalation, the most common route of nanoparticle exposure, has been shown to cause adverse effects on pulmonary functions and the deposited particles in the lung can be translocated to the blood system by passing through the pulmonary protection barriers. Filtration is the simplest and most common method of aerosol control. It is widely used in mechanical ventilation and respiratory protection. However, concerns have been raised regarding the effectiveness of the filters for capturing nanoparticles. This paper reviews the literature on the filtration performance of mechanical filters and respirators against nanoparticles. It includes the discussion about filtration mechanisms, theoretical models, affecting factors of the filtration efficiency, and testing protocols for respirator and filter certification.
\end{abstract}

Key words: Nanoparticle, Filtration efficiency, Respirator, Thermal rebound, Testing standard

\section{Introduction}

Over the past decade, there has been considerable research to improve the performance and functionalities of products by modifying their material structure at nanolevel. This technology, termed nanotechnology, promises tremendous potential benefits for society. According to the U. S. Bureau of Labor Statistics and National Institute for Occupational Safety (NIOSH), in the year 2000, approximately 2.0 million people worked with nano-material products ${ }^{1}$. At the same time, it is believed these workers could be exposed to nanoparticles during the manufacturing of different products, and this could potentially pose a health hazard. The term nanoparticle basically refers to the range of particles below $100 \mathrm{~nm}$ in

*To whom correspondence should be addressed.

E-mail: haghi@bcee.concordia.ca size, at least in one axis. Nanoparticles can be introduced to the atmosphere from different sources such as natural phenomena, human or domestic activities. Epidemiological studies on ultrafine particles, of the same size range as nanoparticles, have clearly shown acute and chronic effects related to the exposure to ultrafine particles. Acute toxicity studies on the effects of nanoparticles on animals have also shown acute effects on different organs; however, chronic studies are still very limited ${ }^{2}$.

Findings from the previously mentioned limited toxicological studies demonstrate that for the same mass, a specific material is normally more toxic at the nano-metric size range than that at the micro-metric size range ${ }^{3,4)}$. It has been reported that nanoparticles's larger surface area and higher number concentration play significant roles in enhancing the toxicity of the nanoparticles ${ }^{5,6}$. This high surface area results in the higher surface reactivity of nanoparticles which influences their potential 
toxicity in the presence of more molecules on the surface ${ }^{6-8)}$. In addition, it has been demonstrated that some other distinct physicochemical-factors such as crystal structure, aggregation potential and surface coatings may influence the toxicity of the particles in the nano-sized range ${ }^{9)}$.

In general, workers are exposed to nanoparticles through a variety of routes in the working environment. These include inhalation, skin absorption, eye contact, and ingestion. Inhalation is considered to be the most common route which nanoparticles reach the various parts of the living organism. When compared with larger particles, a greater portion of inhaled nanoparticles can penetrate into the lung where they are deposited and then translocated to other parts of the body ${ }^{10,11)}$. A portion of these inhaled nanoparticles, are translocated to the brain via olfactory and trigeminus nerve, as observed in rats $^{12,13)}$. Moreover, they can be transported to the blood system by passing through the pulmonary protection barriers ${ }^{11,14,15)}$. In this regard, the toxicity studies in rats and mice have shown that the exposure to nanoparticles cause pulmonary diseases, cardiovascular health effects, and immune system impairments ${ }^{16-18)}$.

A wide range of engineering control systems have been proposed to reduce or prevent the exposure to nanoparticles. These systems include enclosures, local exhaust system, fume hoods, and general ventilation system. Also, Control Banding is a complimentary approach to protect the workers' health ${ }^{19)}$. If engineering controls are insufficient to ensure workers' safety and health, general ventilation system and personal protective equipment using filtration should be used to remove the airborne contaminants. Previous research has confirmed the effectiveness of filters for capturing particles (i.e. traditional airborne contaminants). Standard testing procedures have been developed to measure the effectiveness of filters for capturing macro-particles. The question now is "how effective are these filters for protecting workers against nanoparticles?"

\section{Filtration Mechanisms and Models}

\section{Particle filtration mechanisms}

Previous studies suggested that filtration efficiency is affected by several parameters such as particle characteristics (i.e. chemical composition, diameter, and density), filtration velocity (based on flow rate and surface area), filter characteristics (i.e. fiber diameter, thickness, fiber packing density and porosity), filtration mechanisms and operational conditions (temperature, humidity) ${ }^{20,21)}$. Particle removal is mainly performed by five collection mechanisms: (1) inertia impaction, (2) interception, (3) diffusion, (4) electrostatic attraction and (5) gravitational setting ${ }^{22)}$. The first three collection mechanisms refer generally to mechanical filters and are influenced by particle size and filtration velocity ${ }^{22)}$.

Inertia impaction occurs when the particle changes in streamline direction near a filter fiber and collides with the fiber. This collection mechanism is more effective for larger particles and increases at higher particle velocity. Therefore, it does not significantly contribute to the capture mechanisms for nanoparticles. In general, diffusion is seen as the dominant collection mechanism for particles smaller than $0.2 \mu \mathrm{m}$, and interception and inertia impaction are dominant for the particles larger than $0.2 \mu \mathrm{m}$. It should be noted that the effect of Brownian motion is more significant for smaller particles ${ }^{23-25}$.

\section{Most penetrating particle size}

Previous studies have indicated that the mechanical and electret filters have different performance in aerosol collection within the nano-sized range. In general, for mechanical (non-charged) filters, a particle diameter of $300 \mathrm{~nm}$ is referenced as the Most Penetrating Particle Size (MPPS) at $85 \mathrm{l} / \mathrm{min}^{-1}$; while for electret filters (charged), the lowest filtration efficiency could occur for particle much smaller than $300 \mathrm{~nm}$ in size. The particle penetration through both mechanical and electret filters were investigated for particles between $4.5 \mathrm{~nm}$ to $10 \mu \mathrm{m}$ by Huang $e t a l^{16)}$. They reported that the maximum penetration was reduced from $18.9 \%$ to $5.8 \%$ with the co-operation of an electrostatic attraction force in particle collection. They demonstrated that the MPPS shifted toward the smaller particle using electret filters. The MPPS occurred at $50 \mathrm{~nm}$ for electrets and $200 \mathrm{~nm}$ for mechanical filters.

Kanaoka et al. reported that the maximum penetration occurred for uncharged particles from 30 to $40 \mathrm{~nm}$ in size, whereas singly charged particles showed the peak at much larger size ${ }^{26)}$. Balazy et al. measured the penetration of the MS2 viruses (a non-harmful stimulant of several pathogens) through face-piece respirators ${ }^{27)}$. The study was carried out for particles ranging from 10 to $80 \mathrm{~nm}$ and at the airflow rates of 30 and $851 / \mathrm{min}^{-1}$. The MPPS was observed around $50 \mathrm{~nm}$ for tested respirators. The results also showed that the penetration through the electrets N95 respirators could exceed up to $5.6 \%$ in the MPPS at $85 \mathrm{l} / \mathrm{min}^{-1}$. However, N95 respirators are expected to provide $95 \%$ filtration efficiency against nonbiologic and biologic particles in the MPPS. Balazy et al. measured the filtration performance of N95 respirators for $\mathrm{NaCl}$ particles in the size of 10 to $600 \mathrm{~nm}$ based on a manikin-based protocol ${ }^{28}$. The respirators were tested at the airflow rates of 30 and $85 \mathrm{l} / \mathrm{min}^{-1}$, and the observed MPPS for the respirators with pre-charged filter media was between 30 to $70 \mathrm{~nm}$. Martin and Moyer also inves- 
tigated the most penetrating particle size for electret filters, and found that the MPPS was in the size range from 50 to $100 \mathrm{~nm}$ for electret filters and it shifted to larger sizes from 250 to $350 \mathrm{~nm}$ if the filters were dipped in isopropanol (to reduce the electrical charge on the filter fibres ${ }^{29)}$. Richardson et al. tested N95 facepiece respirators with electret filter media using neutralized $\mathrm{NaCl}$, DOP and MS2 aerosols, and the observed MPPS was smaller than $100 \mathrm{~nm}^{30)}$. Eninger et al. also suggested, for electrets filters, the MPPS appeared to be less than $100 \mathrm{~nm}$ for uncharged and Boltzmann charged aerosols ${ }^{31}$. Rengasamy et al. investigated the penetration of N95 respirators using Boltzmann-charged $\mathrm{NaCl}$ aerosol in the size range of 20 to $400 \mathrm{~nm}^{32}$. They reported the MPPS around $40 \mathrm{~nm}$.

These studies showed that the MPPS strongly depends on factors such as the filter's property, filtration mechanism, airflow rate, fiber charge density, and aerosol particle charge distribution. For non-charged fibers, the MPPS was generally within the size range of 100 to 400 $\mathrm{nm}$, and the MPPS would increase with increasing fiber diameter and decreasing with the airflow rate ${ }^{33,34)}$. For pre-treated filter media, the MPPS significantly depended on the fiber charge conditions ${ }^{29}$.

\section{Single-fiber classic models}

The classical single-fiber efficiency is widely used for filtration application. Hinds defined the filter penetration $(P)$ as $^{22)}$,

$$
P=\exp \left[\frac{-4 \alpha E t}{\pi d_{f}}\right],
$$

where $\alpha$ is the solidity, $E$ is the single-fiber efficiency, $t$ is the thickness of the filter, and $d_{f}$ is the fiber diameter.

The total efficiency $(E)$ is approximately equal to diffusional collection efficiency $\left(E_{d}\right)$ for nanoparticles since diffusion is the dominant filtration mechanism for particles below $100 \mathrm{~nm}$. Previous studies gave a number of theoretical expressions for the single-fiber efficiency due to diffusion. Hinds suggested that $E_{d}$ is a function only of the dimensionless Peclet number $(P e)^{22)}$,

$$
P e=\frac{d_{f} U_{0}}{D},
$$

where $U_{O}$ is the face velocity and $D$ is the particle diffusion coefficient. $D$ can be calculated by the StokesEinstein equation,

$$
D=\frac{k T C_{c}}{3 \pi \eta d_{f}},
$$

where $k$ is the Boltzmann constant, $T$ is the absolute temperature, $\eta$ is the viscosity of air, $C_{c}$ is the slip correc- tion factor which is calculated as,

$$
C_{c}=1+K n\left[1.142+0.558 \exp \left(-\frac{0.999}{K n}\right)\right],
$$

where $K n$ is the Knudsen number defined as the ratio of the gas free path (that is equal to $65 \mathrm{~nm}$ under normal conditions) to the particle radius ${ }^{28)}$.

Davies defines $E_{d}$ as ${ }^{21)}$,

$$
E_{d}=2 P e^{-2 / 3},
$$

$E_{d}$ is given by Cheng and Yeh as ${ }^{35)}$,

$$
E_{d}=2.7 P e^{-2 / 3},
$$

Stechkina carried out a boundary layer analysis for the convective diffusion equation and suggested ${ }^{36)}$,

$$
E_{d}=2.9 K u^{-1 / 3} P e^{-2 / 3}+0.624 P e^{-1},
$$

where $K u$, the Kuwabara hydrodynamic factor, is a dimensionless factor and depends only on solidity $(\alpha)$. It is defined by Hinds ${ }^{22)}$ :

$$
K u=-\frac{\ln \alpha}{2}-\frac{3}{4}+\alpha-\frac{\alpha^{2}}{4},
$$

Wang et al. ${ }^{37)}$ developed an empirical power law model for particles smaller than $100 \mathrm{~nm}$,

$$
E_{d}=0.84 P e^{-0.43},
$$

Wang et al. calculated the single-fiber efficiency from the experimental data and compared it to the theoretical predictions ${ }^{37)}$. The authors suggested neglecting the effect of the in-homogeneity and random orientations of fibers in the filtration performance might lead to the discrepancy between the experimental results and the theoretical ones.

\section{Filtration Efficiency Affecting Factors}

\section{Thermal rebound effect}

From the prediction of the theoretical models, the particle collection efficiency should increase as the size of particle is reduced. However, some recent studies indicate that the filtration efficiency of nano-sized particles can be significantly reduced due to thermal rebound effect. The thermal rebound effect is widely defined by two concepts: critical velocity and kinetic energy ${ }^{38)}$. It has been stated that with the reduction of the particle size below a certain point, the mean thermal velocity due to Brownian motion exceeds the capture velocity, and consequently increases the likelihood of particle detachment from the filter surface ${ }^{23)}$. The possibility that very small particles do not agglomerate on collision because of their mean thermal velocity exceeding the capture velocity was observed by Dahneke ${ }^{39)}$. On the other hand, particles 
with decreasing sizes would have lower adhesion ability when they come in contact with filter surface due to their behaviours: they behave more like molecules. Brown observed that as nano-sized particles approach the dimension of molecular clusters, and when they undergo contact with a fiber surface, they would not adhere to $\mathrm{it}^{23)}$. However, is understudied the exact particle size from which such rebound effect begins to occur.

Several researchers have examined the effect of thermal rebound on the penetration of particle through filters. Wang and Kasper suggested a numerical model for nanoparticle penetration showing that the thermal impact velocity of a particle would exceed the critical sticking velocity in the size range between 1 and $10 \mathrm{~nm}$ depending on elastic and surface adhesion parameters ${ }^{40)}$. Otani et al. examined particle penetration through a circular tube for silver particles. The results showed a higher particle penetration through the tube for particles below $2 \mathrm{~nm}^{41}$. Ichitsubo et al. found that the collection efficiency of the particles was lower than that predicted by the theoretical model for particles below $2 \mathrm{~nm}$ : this could likewise be due to thermal rebound effect ${ }^{42)}$. Similarly, Balazy et al. suggested that this phenomenon occurred for liquid diethyl-hexyl-sebacate (DEHS) aerosol particles by showing that the efficiency of fibrous filters increased with decreasing particle diameter down to $20 \mathrm{~nm}$ and then decreased for particles smaller than that size ${ }^{43)}$. Kim et al. measured the filtration efficiency for nanoparticles down to $1 \mathrm{~nm}$ through glass fibrous filters ${ }^{44)}$. They pointed out that thermal rebound effect occurred at particles sizes below $2 \mathrm{~nm}$ and electrostatic force would become significant in the thermal rebound regime.

However, Alonso et al. detected no particle rebound phenomenon in the same size range as that studied by Ichitsubo $e t a l^{42,45)}$. They reported that the disagreement between the theoretical and experimental studies could be attributed to an unreliable sizing of the particles below 3 $\mathrm{nm}$ by the current available techniques. In addition, Heim et al. challenged Ichitsubo et al., attributing their findings to inaccurate particle size measurement of particles below 2-3 nm caused by an artefact of differential mobility analyzer (DMA) diffusional broadening ${ }^{42,46)}$. Kim et al. investigated nanoparticle filtration characteristics of several commercial filter media including four fiberglass filter media, four electret filter media and one nano-fiber filter media by using silver nanoparticles from $3 \mathrm{~nm}$ to $20 \mathrm{~nm}^{47)}$. They observed that particle penetration decreased continuously down to $3 \mathrm{~nm}$, which suggested that there was no significant evidence of the nanoparticle thermal rebound effect down to $3 \mathrm{~nm}$. Heim et al. also claimed that when accurate sampling methods were used no thermal rebound was detected for $\mathrm{NaCl}$ particles in the size range down to $2.5 \mathrm{~nm}^{48)}$. Huang et al. measured the penetration of $\mathrm{NaCl}$ aerosol particles in the size between $4.5 \mathrm{~nm}$ and $10 \mu \mathrm{m}$ through facepiece respirators and observed no thermal rebound of particles in the range down to $4.5 \mathrm{~nm}^{16)}$. Japuntich et al. measured the filtration efficiency of particles in the size range of 10 to 400 $\mathrm{nm}$ and found no thermal rebound ${ }^{49)}$. Rengasamy et al. investigated the filtration performance of five models of NIOSH-approved N95 and two models of P100 facepiece respirators against monodisperse silver and $\mathrm{NaCl}$ aerosol nanoparticles ${ }^{50)}$. They reported that the penetration levels of silver particles decreased with particle diameter down to $4 \mathrm{~nm}$ for all five N95 models and down to $12 \mathrm{~nm}$ for two P100 models, which was consistent with the single-fiber filtration theory. They claimed that there was no evidence for thermal rebound effect for particles in the size range of 4 to $30 \mathrm{~nm}$.

Shin et al. carried out filtration efficiency experiments for a screen mesh of silver nanoparticles in the range of $3 \mathrm{~nm}$ to $20 \mathrm{~nm}$ at elevated temperature up to $500 \mathrm{~K}^{51)}$. According to the study conducted by Wang and Kasper, it was expected to observe more particle detachment from the fiber surface as a result of exceeding the Brownian motion of nanoparticles at elevated temperatures ${ }^{40}$. They reported the possibility of thermal rebound at high temperatures for $\mathrm{NaCl}$ particles with 1 to $3 \mathrm{~nm}$ size range. However, Shin et al. showed that there was no thermal rebound effect detected in particle size down to $3 \mathrm{~nm}$ at $500 \mathrm{~K}^{51)}$. Shin et al. pointed out that the inconsistency from two studies might be attributed to the different behavior of silver and $\mathrm{NaCl}$ particles at elevated temperature ${ }^{51)}$.

\section{Face velocity and airflow rate}

The face velocity/airflow rate can significantly affect the total filtration performance of fibrous filters since it influences the contribution of diffusion, interception and electrostatic mechanisms ${ }^{45,52)}$. At low face velocity, diffusion and electrostatic forces significantly contribute to the capture efficiency due to higher residence time. With an increasing face velocity, the interception mechanism dominates while the diffusion effect contributes much less to the filter's collection performance. Thus, it is expected that the filtration efficiency drops considerably at higher face velocity. Boskovic et al. tested the filtration efficiency at various velocities ranging from 5 to $20 \mathrm{~cm} / \mathrm{s}^{-1}$ for different shapes of particles (sphere, semi rounded and cubic $)^{38,53)}$. The measured particle size was in the range of $50-300 \mathrm{~nm}$. The results showed that at lower face velocity the filtration efficiency of fibrous filters improved for all different shape of particles. Balazy et $a l$. investigated the filtration efficiency and pressure drop at air velocities between 10 and $30 \mathrm{~cm} / \mathrm{s}^{-1}$ for particles in the range of $10-500 \mathrm{~nm}^{43}$ ). The results demonstrated that 
the total filtration efficiency was reduced by increasing air velocity. Kim et al. conducted the penetration test at face velocity of $5.3,10$, and $15 \mathrm{~cm} / \mathrm{s}^{-1}$ using silver nanoparticles from $3 \mathrm{~nm}$ to $20 \mathrm{~nm}^{47)}$. The results showed that higher face velocity increases particle penetration due to shorter residence time through filters.

For the respiratory filters, particle penetration is determined as a function of the airflow rate instead of face velocity. Several studies have been conducted to investigate the effectiveness of respirators in the removal of nanoparticles at different airflow rates. Eninger et al. evaluated the performance of two models of N95 and one N99 face-piece respirators against three viruses and $\mathrm{NaCl}$ particles ${ }^{31}$. Experiments were carried out at airflow rates of 30,85 and $150 \mathrm{l} / \mathrm{min}^{-1}$. For the N95 model, the highest $\mathrm{NaCl}$ particle penetrations of $1.3,5.9$ and $10.2 \%$ were obtained at respectively airflow rates of 30,85 and $150 \mathrm{l} / \mathrm{min}^{-1}$. For the N99 respirator model, the maximum penetrations were 1.0, 4.3 and $6.6 \%$ at airflow rates of 30,85 and $1501 / \mathrm{min}^{-1}$, respectively. For the viruses, an increase of airflow rate from 85 to $150 \mathrm{l} / \mathrm{min}^{-1}$ strongly affected the performance of all tested respirators. Balazy et al. also measured the penetration through two models of $\mathrm{N} 95$ respirators for $\mathrm{NaCl}$ particles within 10 to $600 \mathrm{~nm}$ at two airflow rates of 30 and $85 \mathrm{l} / \mathrm{min}^{-1}{ }^{28}$ ). The results demonstrated that air flow rate has a strong impact on the particle penetration through the filter face-piece respirators. The particle penetration through both N95 respirators would exceed up to $5 \%$ at the airflow rate of $85 \mathrm{l} / \mathrm{min}^{-1}$. Rengasamy et al. evaluated the performance of several N95 and P100 models against mono-disperse silver aerosols $\mathrm{s}^{50)}$. The test was carried out for particles ranging from 4 to $30 \mathrm{~nm}$ at an airflow rate of $851 / \mathrm{min}^{-1}$. The results demonstrated that the particle penetration decreased for all tested respirators as the particle size decreased to $4 \mathrm{~nm}$. For $\mathrm{N} 95$ face-piece respirators, the particle penetration varied from $1.1 \%$ to $4.0 \%$. For P100 respirators, particle penetration less than $0.3 \%$ was observed.

Most existing guidelines suggest testing filters at the flow rate of $851 / \mathrm{min}^{-1}$ this flow rate simulates human breathing at a heavy work load. Janssen however suggested that respirators should be tested at an airflow rate of $\left.350 \mathrm{l} / \mathrm{min}^{-1} 54\right)$; it is believed a much higher breathing airflow rate may occur in the workplace.

\section{Humidity}

Humidity is one of the factors that may influence the filtration performance. The effects of humidity are not well understood due to lack of investigations. Kim et al. reported no significant effect of humidity on filtration efficiency for particles below $100 \mathrm{~nm}$ by showing almost the same filtration efficiency at different relative humidity
(RH) of $0.04,1.22$, and $92 \%{ }^{44)}$. Inconsistent with Kim et al.'s observation, Brown and Miguel showed that the filtration efficiency improved with increasing relative humidity for coarse particles ${ }^{23,55)}$. Kim et al. explained that an increase of the capillary force at higher RH would increase the adherence between fiber filter and particles $^{44)}$. However, the high attraction between particles and filters due to capillary force is only considerable for larger size particles.

In contrast with those studies for mechanical filters, the studies for electret filters (charged filters) demonstrated the filtration performance decreases as humidity increases. The reason is that higher humidity would lead to the reduction in the charges on the filter's fiber and particles. Ikezaki et al. and Lowkis et al. also confirmed that the potential of the electret filters on the collections of the particles fell as the surface charge was decreased with the increase of $\mathrm{RH}^{56,57)}$. Yang and Lee, however, reported that RH had no effect on the aerosol penetration through the electret filter for monodisperse $\mathrm{NaCl}$ particles ranging from $50 \mathrm{~nm}$ to $100 \mathrm{~nm}$ by showing that the aerosol penetration was almost the same at two RH of $30 \%$ and $70 \%{ }^{58)}$. Yang and Lee explained that other studies mainly charged the electret filters either by using corona or triboelectric charging methods. These methods made the ions and electrons on the fibers easily removable by the water molecules (resulting in the decrease of surface charge with a higher $\mathrm{RH})^{58)}$. In their study, Yang and Lee charged filters by coating with the negatively carbonchain-group ions which makes the surface charge less affected by the humidity ${ }^{58)}$. Another possibility is that $\mathrm{NaCl}$ particles at $\mathrm{RH}$ of $70 \%$ may undergo deliquescence and grow to larger particles so that the measured filtration efficiency is overestimated.

\section{Particle charge states}

Particle charge is another factor that significantly affects the particle filtration efficiency of mechanical and electret filters ${ }^{59,60)}$. The increase in filtration efficiency is associated with additional electrostatic attraction resulting from coulomb and image force attraction ${ }^{23)}$. Kim et al. demonstrated the difference in the collection efficiency through a glass fiber filter at different charge states for particle ranging from 2 to $100 \mathrm{~nm}^{44)}$. They found that the filtration efficiency for uncharged particles was much lower than that for charged particles, and this discrepancy decreased with the reduction in particle size. They explained that this phenomenon was due to the fact that diffusion is the most dominant deposition mechanism for nanoparticles and this process increases the effect of diffusion for smaller particles. In addition to particle size, face velocity also had significant effect on the filtration efficiency for charged particles. It was found that high- 
er face velocity would lead to filtration less affected by particle charge because of shorter residence time ${ }^{52}$. The penetration of neutralized and non-neutralized particle in the range of 10 to $600 \mathrm{~nm}$ through electret and mechanical filters was investigated by Balazy et al. ${ }^{28}$. Higher filtration efficiency was observed when testing the penetration of the neutralized particles for the electret filters. However, for the mechanical filters, they reported no significant change between the neutralized and non-neutralized particles. Yang and Lee measured the filtration efficiency for $\mathrm{NaCl}$ aerosols with the Boltzmann-equilibrium, neutral, or singly charged state. They showed that singly charged aerosols would lead to higher filtration efficiency than neutral aerosols: the Coulomb capture force was dominant for nanoparticles ${ }^{58}$.

\section{Testing Standards}

In June 1995, the National Institute for Occupational Safety and Health (NIOSH) updated the certification test criteria for negative pressure air-purifying particulate respirators with the enactment of $42 \mathrm{CFR} 84^{61)}$. NIOSH certifies three classes of filters labeled $\mathrm{N}, \mathrm{R}$, and $\mathrm{P}$, and three levels of filter efficiency, 95\%, 99\% and $99.97 \%$ for each class of filter. N, R and P correspond to filters respectively not resistant, limited resistance and resistant to oil aerosols. NIOSH approves the 'N-series' respiratory filters (N95, N99 and N100) based on tests performed with a polydisperse distribution of $\mathrm{NaCl}$ particles with a count median diameter (CMD) of $0.75 \pm 0.020 \mu \mathrm{m}$. R- and Pdesignated respirators (R95, R99, R100, P95, P99, P100) are tested with a polydisperse distribution of dioctyl phthalate (DOP) particles with a CMD of $0.165 \pm 0.020 \mu \mathrm{m}^{61)}$. Tests are performed at a constant flow rate of $851 / \mathrm{min}^{-1}$ corresponding to an average breathing rate of an individual involved with a heavy work load. In the NIOSH certification test, the filtration efficiency of N95 facepiece respirator is measured under 'worst-case' scenario using Boltzmann charge-neutralized particles. Balazy et al. showed that an emerging Coulomb force would be induced if both filters and particles were charged. This would significantly overestimate the respirator performance ${ }^{28)}$.

As pointed out earlier, the MPPS for a specific filter system depends on the filter's property, filtration mechanism, air flow rate, fiber charge density, and aerosol particle charge distribution. For electrets filters, "the existing certification test may not assess filtration efficiency for particle sizes that represent the worst-case scenario $^{31) " . ~ T h e ~ M P P S ~ f o r ~ e l e c t r e t ~ f i l t e r s ~ i s ~ m u c h ~ s m a l l e r ~}$ than that for mechanical filters. However, the NIOSH certification test assumes the MPPS of approximately $300 \mathrm{~nm}$ for all filters and filters types: this may not be true for electret filters. Forward-light scattering photometers are used in the NIOSH testing protocol to measure aerosol concentrations before and after the tested respirator. Generally, photometer signal is only capable of measuring the particles with diameters larger than $100 \mathrm{~nm}$ so that photometric method employed in the NIOSH protocol is not suitable for nanoparticles application ${ }^{31}$. Eninger et al. showed that $68 \%$ and $10 \%$ (by count) of $\mathrm{NaCl}$ and DOP particles are below $100 \mathrm{~nm}$ in NIOSH testing protocol $^{31)}$.

For mechanical ventilation system filters, standards exist for the different types of air filters ${ }^{62)}$. Most of the filters are tested with particles size larger than $300 \mathrm{~nm}$. Only High-Efficiency Particulate Air (HEPA) and UltraLow Penetration Air (ULPA) filters are tested with particles smaller than $300 \mathrm{~nm}^{63)}$. According to ASHRAE Standard 52.2, the performance tests are to be conducted at one of seven airflow rates: $0.60 \mathrm{~m} / \mathrm{s}^{-1}(118 \mathrm{fpm})$, $1.25 \mathrm{~m} / \mathrm{s}^{-1}$ (246 fpm), $1.50 \mathrm{~m} / \mathrm{s}^{-1}$ (295 fpm), $1.90 \mathrm{~m} / \mathrm{s}^{-1}$ (374 fpm), $2.50 \mathrm{~m} / \mathrm{s}^{-1}$ (492 fpm), $3.20 \mathrm{~m} / \mathrm{s}^{-1}$ (630 fpm), and $3.80 \mathrm{~m} / \mathrm{s}^{-1}(748 \mathrm{fpm})^{63)}$.

The HEPA and ULPA filters are used for collection of particles with diameter less than $300 \mathrm{~nm}$. HEPA filters should have filtration efficiency of $99.97 \%$ for particle size $300 \mathrm{~nm}$ in size at a face velocity of $5.3 \mathrm{~cm} / \mathrm{s}^{-1}$. The filtration efficiency of ULPA filters can exceed up to 99.999\% with particle size of $0.12 \mu \mathrm{m}$.

\section{Conclusion and Future Direction}

A review of previous research work on the filtration performance of filters and respirators against nanoparticles is presented. It is very difficult to draw any scientific conclusion from previous studies. This inconclusiveness is due to the lack of understanding on the effectiveness of filter media for capturing nanoparticles. The methodologies and protocols adopted are not standardized: the experiments are carried out at various conditions (temperature, airflow rate, $\mathrm{RH}$, measurement techniques, etc.). This has limited the validation of the procedure and has made it difficult to compare the results of these various studies. With the exponential growth in the manufacturing sector of nano-products, it is important to study the impact of the above mentioned parameters on filter effectiveness under conditions normally found in the working environment. This is especially important given that one of the most challenging issues currently facing occupational health and safety is the lack of knowledge about the effect of airflow rate, temperature, humidity, and the duration of use on the performance of filter media for capturing nanoparticles. The priority on the future research project should be development of an experimental set-up to characterize the filter efficiency in different 
experimental conditions. This will assist in the development of expertise and knowledge in nanoparticle filtration. It is also essential to develop a standardized method for measuring the effectiveness of these filters for respiratory protection and HVAC system and comparing their performances. To our knowledge, there are no current standards to quantify or classify the performance of these filters against nanoparticles.

Previous studies were limited to bench-top tests under high contaminant concentration and at relatively low airflow rates. Due to the conditions forementioned, the results of these studies cannot be inferred for real applications. The majority of previous investigations demonstrated that the filter respirators were efficient for capturing particles at constant flow rates ranging between 30 and $85 \mathrm{l} / \mathrm{min}^{-1}$. Although a flow rate of $85 \mathrm{l} / \mathrm{min}^{-1} \mathrm{sim}$ ulates the relatively high breathing rate at strenuous work load used by NIOSH for respirator certification, it is believed that the inhalation rate can exceed $350 \mathrm{l} / \mathrm{min}^{-1}$ at a heavy work load ${ }^{54)}$. Richardson showed that increasing airflow rates at both constant and cyclic conditions could lead to higher particle penetrations ${ }^{30}$. Further research is necessary to investigate the filter efficiency depending on the duration of use and at higher airflow rates $\left(300-4001 / \mathrm{min}^{-1}\right)$ which replicates peak breathing flows at high working loads. It is also important to investigate the performance of respiratory mask filters under a realistic airflow pattern (cyclic airflow).

Last but not the least, improved selection on respirators against nanoparticles should be developed to ensure high levels of respiratory protection for workers and exposed persons.

\section{Acknowledgements}

The authors would like to express their gratitude to the Institut de Recherche Robert-Sauvé en Santé et Sécurité du Travail and Nano-Quebec for the financial support.

\section{References}

1) Bureau Of Labor Statistics, National Institute for Occupational Safety and Health (NIOSH) and the Department Of Labor (2003) Respirator Usage in Private Sector Firms. NIOSH, Morgantown.

2) Ostiguy C, Soucy B, Lapointe G, Woods C, Ménard L (2008) Les effets sur la santé reliés aux nanoparticules, Rapport IRSST R-558, 2nd Ed., IRSST, Montreal (in French).

3) Donaldson K, Stone V, Clouter A, Renwick L, MacNee W (2001) Ultrafine particles. Occup Environ Med 58, 211-6.

4) Oberdorster G (2000) Toxicology of ultrafine particles: in vivo studies. Philos Trans $\mathrm{R}$ Soc Lond A358,
2719-40.

5) McCullough NV, Brosseau LM, Vesley D (1997) Collection of three bacterial aerosols by respirator and surgical mask filters under varying conditions of flow and relative humidity. Ann Occup Hyg 41, 677-90.

6) Tran CL, Buchanan D, Cullen RT (2000) Inhalation of poorly soluble particles. II. Influence of particle surface area on inflammation and clearance. Inhal Toxicol 12, 1113-26.

7) Warheit DB, Webb TR, Colvin VL, Reed KL, Sayes CM (2007) Pulmonary bioassay studies with nanoscale and fine quartz particles in rats: toxicity is not dependent upon particle size but on surface characteristics. Toxicol Sci 95, 270-80.

8) Warheit DB, Webb TR, Reed KL, Frerichs S, Sayes CM (2007) Pulmonary toxicity study in rats with three forms of ultrafine- $\mathrm{TiO}_{2}$ particles: differential responses related to surface properties. Toxicology 230, 90-104.

9) Warheit DB, Sayes CM, Reed KL, Swain KA (2008) Health effects related to nano-particle exposures: environmental, health and safety considerations for assessing hazards and risks. Pharmacol Ther 120, 35-42.

10) Nemmar A, Vanbilloen H, Hoylaerts MF, Hoet PHM, Verbruggen A, Nemery B (2001) Passage of intratracheally instilled ultrafine particles from the lung into the systemic circulation in hamster. Am J Respir Crit Care Med 164, 1665-8.

11) Oberdorster G, Sharp Z, Atudorei V, Elder A, Gelein R, Lunts A, Kreyling W, Cox C (2002) Extrapulmonary translocation of ultrafine carbon particles following whole-body inhalation exposure of rats. J Toxicol Environ Health A 20, 1531-43.

12) Oberdorster G, Sharp Z, Atudorei V, Elder A, Gelein R, Kreyling W, Cox C (2004) Translocation of inhaled ultrafine particles to the brain. Inhal Toxicol 16, 437-45.

13) Oberdorster G (2005) Nanotoxicology: an emerging discipline evolving from studies of ultrafine particles. Environ Health Perspect 113, 823-39.

14) Takenaka S, Karg D, Roth C, Schulz H, Ziesenis A, Heinzmann U, Chramel P, Heyder J (2001) Pulmonary and systemic distribution of inhaled ultrafine silver particles in rats. Environ Health Perspect 109, 547-51.

15) Nemmar A, Hoet PHM, Vanquickenborne B, Dinsdale D, Thomeer M, Hoylaerts MF, Vanbilloen $\mathrm{H}$, Mortelmans L, Nemery B (2002) Passage of inhaled particles into the blood circulation in humans. Circulation 105, 411-4.

16) Huang $\mathrm{SH}$, Chen $\mathrm{CW}$, Chang $\mathrm{CP}$, Lai CY, Chen $\mathrm{CC}$ (2007) Penetration of $4.5 \mathrm{~nm}$ to $10 \mu \mathrm{m}$ aerosol particles through fibrous filters. J Aerosol Sci 38, 719-27.

17) Dockery DW, Pope AC (1994) Acute respiratory effects of particulate air pollution. Annu Rev Publ Health 15, 107-32.

18) Hagdnagy W, Stiller-Winkler R, Kainka R, Ranft U, Idel H (1998) Influence of urban particulate air pollution (PM10; PM2.5) on the immune system of children. J Aerosol Sci 29 (Suppl 2), S997-8. 
19) Tait K (2004) Control banding: an improved means of assessing and managing health and safety risks at Pfizer. Presented at the Second International Control Banding Workshop: Validation and Effectiveness of Control Banding. 1-2 March 2004, Cincinnati.

20) Dullien FAL (1989) Introduction to Industrial Gas Cleaning. Academic Press, San Diego.

21) Davies CN (1973) Air Filtration. Academic Press, London.

22) Department Of Health and Human Services (DHHS) (2003) Guidance for filtration air cleaning system to protect building environments from airborne chemical, biological, and radiological attacks. NIOSH, Cincinatti.

23) Hinds WC (1999) Aerosol Technology: Properties, Behavior, and Measurement of Airborne Particles, 2nd Ed., Wiley, New York.

24) Brown RC (1993) Air Filtration: an Integrated Approach to the Theory and Applications of Fibrous Filters. Pergamon, Oxford.

25) Lee KW, Liu B (1980) On the minimum efficiency and the most penetrating particle size for fibrous filters. $\mathrm{J}$ Air Pollut Control Assoc 30, 377-81.

26) Kanaoka C, Emi H, Otani Y, Liyama T (1987) Effect of charging state of particles on electret filtration. J Aerosol Sci 7, 1-13.

27) Balazy A, Toivola M, Adhikari A, Sivasubramani SK, Reponen T, Grinshpun SA (2006) Do N95 respirators provide $95 \%$ protection level against airborne viruses, and how adequate are surgical masks? Am J Infect Control 34, 51-7.

28) Balazy A, Toivola M, Reponen T, Podgorski A, Zimmer A, Grinshpun SA (2006) Manikin-based performance evaluation of N95 filtering-facepiece respirators challenged with nanoparticles. Ann Occup Hyg 50, 259-69.

29) Martin SB, Moyer ES (2000) Electrostatic respirator filter media: filter efficiency and most penetrating particle size effects. Appl Occup Environ Hyg 15, 609-17.

30) Richardson AW, Eshbaugh JP, Hofacre KC, Gardner PD (2006) Respirator filter efficiency testing against particulate and biological aerosols under moderate to high flow rates. U.S. Army Edgewood Chemical Biological Center Report for Contract No. SP0700-00-D-3180, Task No. 335, ECBC-CR-085. http://www.cdc.gov/ niosh/npptl/researchprojects/pdfs/CR-085Gardner.pdf. Accessed July 20, 2008.

31) Eninger RM, Honda T, Adhikari A, Tanski H, Reponen T, Grinshpun SA (2008) Filter performance of N99 and N95 face-piece respirators against viruses and ultrafine particles. Ann Occup Hyg 52, 385-96.

32) Rengasamy S, Verbofsky R, King WP, Shaffer RE (2007) Nanoparticle penetration through NIOSHapproved N95 filtering-facepiece respirators. J Int Soc Respir Prot 24, 49-59.

33) Grafe T, Gogins M, Barris M, Schaefer J, Canepa R (2001) Nanofibers in filtration applications in transportation. 1-15, Proceedings of the Filtration 2001 International Conference and Exposition of the INDA
(Association of the Nowovens Fabric Industry), Chicago.

34) Howard J (2003) Guidance for filtration an air-cleaning systems to protect building environments from airborne chemical, biological, or radiological attacks. http:// www.cdc.gov/niosh/docs/2003-136/pdfs/2003-136.pdf. Accessed February 15, 2009.

35) Cheng YS, Yeh HC (1980) Theory of a screen-type diffusion battery. J Aerosol Sci 11, 313-20.

36) Stechkina IB (1966) Diffusion precipitation of aerosols in fiber filters. Doklady Akademii Nauk SSSR 167, 1327.

37) Wang J, Chen DR, Pui DYH (2007) Modeling of filtration efficiency of nanoparticles in standard filter media. J Nanopart Res 9, 109-15.

38) Boskovic L, Agranovski IE, Braddock RD (2007) Filtration of nanosized particles with different shape on oil coated fibres. J Aerosol Sci 38, 1220-9.

39) Dahneke B (1971) The capture of particles by surfaces. J Colloid Interface Sci 37, 342-53.

40) Wang HC, Kasper G (1991) Filtration efficiency of nanometer-size aerosol particles. J Aerosol Sci 22, 31-41.

41) Otani Y, Cho SJ, Emi H (1994) Removal of nanometer size particles and ions from air. 21-5, Proceedings of the 12th ISCC, Yokohama.

42) Ichitsubo $\mathrm{H}$, Hashimoto $\mathrm{M}$, Alonso M, Kousaka $\mathrm{Y}$ (1996) Penetration of ultrafine particles and ion clusters through wire screen. Aerosol Sci Technol 24, 119-27.

43) Balazy A, Podgorski A, Gradon L (2004) Filtration of nanosized aerosol particles in fibrous filters. I Experimental results. J Aerosol Sci 35 (Suppl 2), S967-8.

44) Kim CS, Bao L, Okuyama K, Shimada M, Niinuma $H$ (2006) Filtration efficiency of a fibrous filter for nanoparticles. J Nanopart Res 8, 215-21.

45) Alonso MY, Kousaka Y, Hashimoto T, Hashimoto N (1997) Penetration of nanometer-sized aerosol particle through wire screen and laminar flow tube. Aerosol Sci Technol 27, 471-80.

46) Heim M, Mullins BJ, Kasper G (2006) Comment on: penetration of ultrafine particles and ion clusters through wire screens by Ichitsubo et al. Aerosol Sci Technol 40, 144-5.

47) Kim SE, Harrington MS, Pui DYH (2007) Experimental study of nanoparticles penetration through commercial filter media. J Nanopart Res 9, 117-25.

48) Heim M, Mullins BJ, Wild M, Meyer J, Kasper G (2005) Filtration efficiency of aerosol particles below 20 nanometers. Aerosol Sci Technol 39, 782-9.

49) Japuntich DA, Franklin L, Pui DYH, Kuehn T, Kim SC (2007) A comparison of two nano-sized particle air filtration tests in the diameter range of 10 to $400 \mathrm{~nm}$. J Nanopart Res 9, 93-107.

50) Rengasamy S, King WP, Eimer BC, Shaffer RE (2008) Filtration performance of NIOSH-approved N95 and P100 filtering facepiece respirators against 4 to 30 
nanometer-size nanoparticles. J Occup Environ Hyg 5, 556-64.

51) Shin WG, Mulholland GW, Kim SC, Pui DYH (2008) Experimental study of filtration efficiency of nanoparticles below $20 \mathrm{~nm}$ at elevated temperatures. J Aerosol Sci 39, 488-99.

52) Kousaka Y, Okuyama K, Shimada M, Takii Y (1989) Development of a method for testing very high-efficiency membrane filters for ultrafine aerosol particles. J Chem Eng Jpn 23, 568-74.

53) Boskovic L, Agranovski IE, Altmana IS, Braddock RD (2008) Filter efficiency as a function of nanoparticle velocity and shape. J Aerosol Sci 39, 635-44.

54) Janssen L (2003) Principles of physiology and respirator performance. Occup Health Saf 72, 73-81.

55) Miguel AF (2003) Effect of air humidity on the evolution of permeability and performance of a fibrous filter during loading with hygroscopic and non-hygroscopic particles. J Aerosol Sci 34, 783-99.

56) Ikezaki K, Iritani K, Nakamura T, Hori T (1995) Charge stability of TPX film electrets. J Electrostat 35, 41-6.

57) Lowkis B, Motyl E (2001) Electret properties of polypropylene fabrics. J Electrostat 29, 353-5.
58) Yang S, Lee GWM (2005) Filtration characteristics of a fibrous filter pretreated with anionic surfactants for monodisperse solid aerosols. J Aerosol Sci 36, 419-37.

59) Chen CC, Huang SH (1998) The effect of particle charge on the performance of a filtering facepiece. Am Ind Hyg Assoc J 59, 227-33.

60) Fjeld R, Owens $T$ (1988) The effect of particle charge on penetration in an electret filter. IEEE Transactions on Industry Applications 24, 725-31.

61) Code of Federal Regulations (1996) Approval of Respiratory Protective Devices. Title 42, Part 84, 528-93.

62) The National Air Filtration Association (NAFA), User's Guide for ANSI/ASHRAE 52.2. (2007) Method of testing general ventilation air-cleaning devices for removal efficiency by particle size. http://www.nafahq.org/ LibaryFiles/Articles/Article006.htm. Accessed July 20, 2008.

63) ASHRAE. Standard 52.2. (2007) Method of testing general ventilation air-cleaning devices for removal efficiency by particle size. American Society of Heating, Refrigerating, and Air-Conditioning Engineers, Inc., Atlanta. 